\title{
GABA-Mediated Negative Feedback from Horizontal Cells to Cones in Carp Retina
}

\author{
Motohiko Murakami, Yukio Shimoda,* Kei NaKatani, ** \\ Ei-ichi MiYaChI, and Shu-ichi Watanabe \\ Department of Physiology, Keio University School of Medicine, \\ Shinjuku-ku, Tokyo, 160 Japan \\ *Department of Physiology, Kyorin University School of Medicine, \\ Mitaka, Tokyo, 181 Japan \\ **Department of Physiology, Tokyo Women's Medical College, \\ Shinjuku-ku, Tokyo, 162 Japan
}

\begin{abstract}
In the isolated, perfused retina of the carp, properties of the feedback pathway from horizontal cells to cones were investigated by means of electrophysiological and neuropharmacological methods. When horizontal cells were hyperpolarized by illumination with an annulus, a depolarizing synaptic potential was produced in cones at the center of the annulus, suggesting that horizontal cells receive inputs from cones and exert a negative feedback to cones. On the other hand, a hyperpolarizing response (IPSP) was detected in cones, when a transient depolarization (EPSP) was induced in horizontal cells by application of a transretinal current pulse, which activated the release of transmitter from the photoreceptor terminals. The IPSP was abolished when the retina was perfused with a GABA-containing Ringer solution, because of desensitization of the feedback synapse. GABA also hyperpolarized the cone membrane, indicating the presence of a GABA-sensitive site in the cone. These results suggest that the GABA-mediated negative feedback operates from horizontal cells to cones in the dark, and ceases its function in the light.

Key Words: retina, feedback, cone, horizontal cell, GABA.
\end{abstract}

The amplitude and waveform of the light-induced hyperpolarization in cones depend on the light intensity as well as the area of illumination. When small areas of turtle retina were illuminated, the stimulated cones responded solely with graded hyperpolarization (BAYLOR and FUORTES, 1970). On the other hand, light stimuli either of a large spot or of an annulus covering the periphery of a cone's receptive field evoked depolarizing potential in the cone (BAYLOR et al., 1971; O'Bryan, 1973; Gerschenfeld and Piccolino, 1980; Piccolino and Gerschen-

Received for publication July 23, 1982

村上元彦, 霜田幸雄, 中谷 敬, 宮地栄一, 渡辺修一 
FELD, 1980; GERSCHENFELD et al., 1980). Similar observations have been reported in the retina of the pikeperch (BURKHARDT, 1977; BURKHARDT and HASSIN, 1978) and the larval tiger salamander (LASANSKY, 1981). These observations suggest that the signals of many cones converge onto a horizontal cell, producing in it a hyperpolarization, which, in turn, causes a depolarizing synaptic potential in the cones through a negative feedback. Feedback has been suggested to be essential in the neural mechanisms which convert the trichromatic process at the level of cones into the opponent color process in horizontal cells (BAYLOR et al., 1971; Fuortes et al., 1973; O'Bryan, 1973; Fuortes and Simon, 1974; Gerschenfeld and Piccolino, 1980; Piccolino and Gerschenfeld, 1980). Not much is known about the mechanisms of color opponency of the fish retina, but a similar function of the feedback has been proposed (Gouras, 1972; BURKHARDT, 1977; DJAMGOZ and RUDDOCK, 1979).

The forming of an electrophysiological strategy for revealing the negative feedback pathways in the carp retina has been tried by TRIFONOV and BYzov (1977), on the assumption that, if horizontal cells have inhibitory synapses onto cones, a depolarization of the horizontal cells would lead to an inhibitory postsynaptic potential (IPSP) in cones. However, these workers reported that no measurable potential deflection was detected in cones of carp retina. We repeated a similar experiment on the carp retina and were able to observe IPSP's in the cone. In the first part of this paper, we will describe electrophysiological and neuropharmacological characteristics of the feedback pathway.

Another main subject of this paper is to analyze the effect of $\gamma$-aminobutyric acid (GABA) on activities of the feedback synapse. There are numerous reports suggesting that GABA is a putative neurotransmitter in the vertebrate retina. The early studies were reviewed by GraHAM (1974) and VoAden (1976). Our interest has been quickened by a series of reports published by Lam and others, in which they suggested that, in the fish retina, GABA is a neurotransmitter mediating the feedback synaptic pathways from horizontal cells to cones (LAM and SteInMAN, 1971; LAM, 1975, 1976; MARC et al., 1978; LAM et al., 1979).

Our experiments were designed to test the action of GABA on the IPSP in the cone. We found that the IPSP was abolished by perfusion of the retina with a GABA-containing solution, because of desensitization of the feedback synapse. Furthermore, as will be described in the following paper (MURAKAMI et al., 1982), GABA and its antagonists caused remarkable changes in spectral responses of horizontal cells, suggesting that the GABA-mediated feedback pathway is involved in neural mechanisms of color vision.

A part of the experiment has been briefly reported in a preliminary form (MuraKami et al., 1978; Shimoda et al., 1982). This paper will fully describe the experiment, and includes further supporting evidence obtained thereafter as well as a more detailed discussion. 


\section{METHODS}

The experimental arrangements are schematically illustrated in Fig. 1.

Preparation. Experiments were performed on retinas of carp, Cyprinus carpio, weighing about $500 \mathrm{~g}$ each. After dark-adapting the carp in an aerated aquarium for about $1 \mathrm{hr}$, the eyes were quickly enucleated and the isolated retinas were removed under a dim red light.

Perfusion system. The retina was mounted, receptor side up, in a Teflon perfusion chamber with a capacity of about $0.7 \mathrm{ml}$. The Ringer solution was continuously supplied to the chamber through a peristaltic pump at a flow rate of about $1 \mathrm{ml} / \mathrm{min}$. The pulsating flow from the pump was smoothened by a damper consisting of narrow passages and air cavities excavated in a Perspex block, analogous to an electric smoothing circuit consisting of resistors and capacitors. The solution was drained off by a suction pump through a hypodermic needle placed in an accessory chamber connected to the main one through a culvert.

The composition of the normal Ringer solution was: $102 \mathrm{~mm} \mathrm{NaCl}, 2.6 \mathrm{~mm}$ $\mathrm{KCl}, 1.0 \mathrm{mM} \mathrm{CaCl}, 1.0 \mathrm{~mm} \mathrm{MgCl}_{2}, 28 \mathrm{~mm} \mathrm{NaHCO}$, and $5.0 \mathrm{~mm}$ Tris. The solution was bubbled with $95 \% \mathrm{O}_{2}$ and $5 \% \mathrm{CO}_{2}$, and the final $\mathrm{pH}$ was adjusted to 7.9. The test solutions containing GABA (5 mM) and $\mathrm{CoCl}_{2}(2 \mathrm{mM})$ were made by dissolving these chemicals into the normal solution without molarity compensation, and the $\mathrm{pH}$ was re-adjusted if necessary. These solutions were freshly prepared prior to each experiment. The temperature of the solutions was regulated at about $20^{\circ} \mathrm{C}$ by a water jacket attached beneath the perfusion chamber.

Intracellular recording and transretinal current application. Intracellular recording was done with glass micropipette electrodes filled with $4 \mathrm{~m}$ potassium acetate for conventional recordings, or with a $5 \%$ solution of Procion Yellow MX4R for intracellular stainings. The indifferent electrode was a chlorided silver plate placed on the bottom of the perfusion chamber, which also served as one

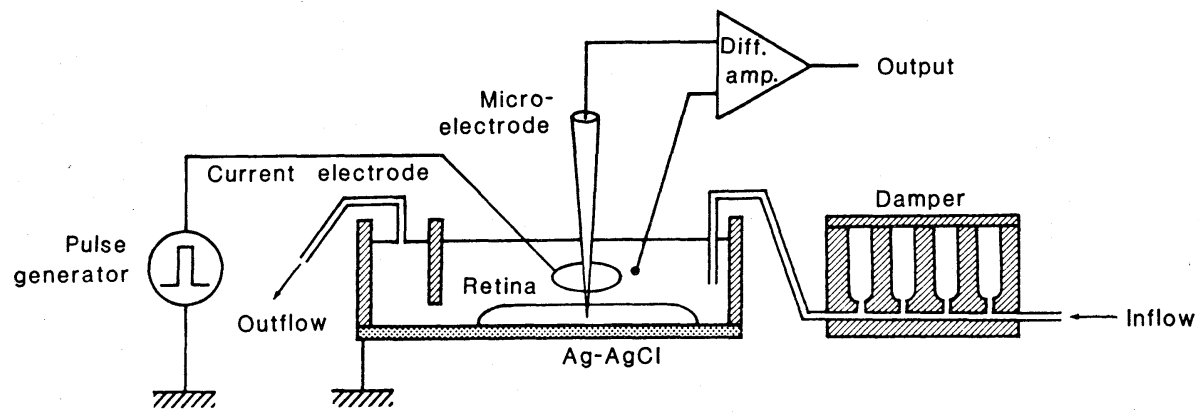

Fig. 1. Schematic representation of the experimental arrangement for intracellular recordings of single cells in a perfused carp retina and for transretinal current application. Further explanation in the text. 
of a pair of current electrodes, when a transretinal current pulse was applied. Another current electrode was a chlorided silver wire ring of $2.6 \mathrm{~mm}$ diameter placed above the retina. The recording electrode was positioned at the center of the ring. The current pulse was about $1 \mathrm{~mA}$ in strength and $0.5 \mathrm{msec}$ in duration. In order to minimize current artifacts, differential recording was used between the intracellular electrode and a chlorided silver wire electrode appropriately positioned in the Ringer bath. Responses were recorded through a D.C. preamplifier and displayed on an oscilloscope. The records were simultaneously stored on FM magnetic tapes. They were later played back with a reduced tape speed and displayed by a pen recorder for illustrations. Whenever necessary, the responses were averaged by a computer (ATAC-250, Nihon Kohden Kogyo Co.).

Light stimulation and cell identification. The two-channel photostimulator used has been described elsewhere (Tomita et al., 1967). First, cones and horizontal cells were identified based on the difference of their area effects; the retina was alternately illuminated by a spot ( $300 \mu \mathrm{m}$ in diameter) and an annulus (inner diameter $1 \mathrm{~mm}$, outer diameter $4 \mathrm{~mm}$ ) of white light. We did not compensate for light scattering and the shadow of the silver wire ring current electrode, because these were not crucial to the present experiment. For further identification of cell types, spectral scans were made with monochromatic lights adjusted to equal quantum flux $\left(2.9 \times 10^{5}\right.$ photons $\left.\cdot \mu \mathrm{m}^{-2} \cdot \mathrm{sec}^{-1}\right)$, in steps of $20 \mathrm{~nm}$ from 400 through $740 \mathrm{~nm}$. Intensities were attenuated by neutral density filters, when necessary.

The most conclusive cell identification was achieved by intracellular stainings. Procedures of Procion dye injections and the following histology have been described elsewhere (MURAKAMI and SHIMODA, 1977).

\section{RESULTS}

\section{Depolarization of cones induced by annular illumination}

When small areas of turtle retina were illuminated, the stimulated cones responded with graded hyperpolarization (BAYLOR and FUORTES, 1970). On the other hand, light stimuli covering large areas of the periphery of their receptive fields evoked depolarizing potentials in cones (BAYLOR et al., 1971; O'BRYAN, 1973). Identical observations have also been reported in pikeperch retina (BURKHARDT, 1977; BURKHARDT and HASSIN, 1978).

Here a similar experiment was performed on the carp retina with similar results, as shown in Fig. 2. When the retina was illuminated by a spot of white light, the cone was simply hyperpolarizing (Trace A). Then an additional annular illumination given during the spot illumination induced a depolarizing potential in the cone (Trace B). These results were similar to those obtained by O'BRYAN (1973), but the depolarizing potential was never accompanied by $\mathrm{Ca}^{2+}$ spikes which 

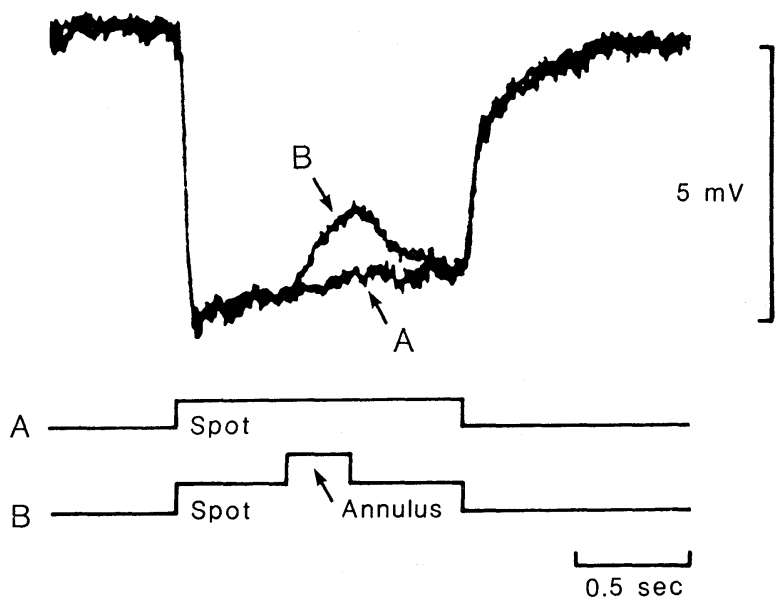

Fig. 2. Superimposed record of responses of a red-sensitive cone solely to illumination with a spot (Trace A), and to a spot with an additional surrounding annulus (Trace B), showing that a depolarizing synaptic potential is produced by the annulus. The lower traces show the timings of the spot of white light $(300 \mu \mathrm{m}$ in diameter; relative log intensity, -1.0) and the annulus (inner diameter, $1 \mathrm{~mm}$; outer diameter, $4 \mathrm{~mm}$; relative $\log$ intensity, -1.25$)$.

have been reported to occur frequently in turtle cones (GERSCHENFELD and Piccolino, 1980; Piccolino and Gerschenfeld, 1980; Gerschenfeld et al., 1980). The depolarizing potentials were observed in all types of cones, although being detectable in about $10 \%$ of each type of cone penetrated by microelectrodes. Nevertheless, these observations on the carp retina suggested that, similarly to the turtle retina, the signals of many cones converge onto a horizontal cell, producing in it a hyperpolarization, which, in turn, causes a depolarizing synaptic potential in a cone by feedback. However, the system under observation involved many neural elements and the experiment did not apply to further clarification of the mechanisms of the feedback.

\section{Responses in cones evoked by transretinal current pulse}

In order to investigate the neural system and to enable us to better understand the synaptic properties of the feedback, we repeated an experiment similar to that which had been tried by Trifonov and Byzov (1977) (see Introduction).

The photoreceptors of the vertebrate retina are so regularly arranged that a transretinal current pulse, flowing from the receptor side to the vitreal side, effectively depolarizes the cone terminals, activates transmitter release, and thereby generates a transient depolarization (EPSP) in the horizontal cells (TRIFONOV, 1968; Byzov and Trifonov, 1968; Trifonov et al., 1974; KANEKo and ShimazaKi, 1976; WATANABE et al., 1978). The transient EPSP's thus evoked in the horizontal cells are shown in Fig. 3; the EPSP in the dark was followed by a transient hyper- 

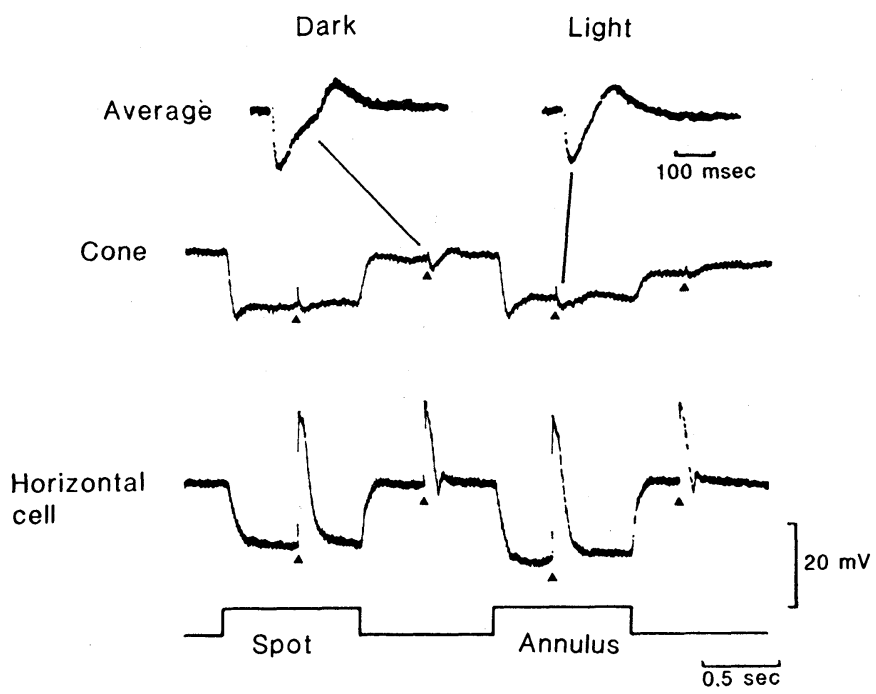

Fig. 3. Responses in a red-sensitive cone and an $\mathrm{H} 1$ horizontal cell evoked by transretinal current pulses, recorded with the experimental arrangement shown in Fig. 1. The retina was illuminated first by a spot of white light $(300 \mu \mathrm{m}$ in diameter; relative log intensity, -1.0 ) and then by an annulus (i.d., $1 \mathrm{~mm}$; o.d., $4 \mathrm{~mm}$; relative $\log$ intensity, -1.0 ) as shown by the lowermost trace. The triangles attached to the traces indicate the timings of transretinal current pulses. The voltage calibration applies to both the cone and horizontal cell responses. The uppermost traces are records of the average of twenty responses in the cone during dark and light.

polarization, but not in the light. The difference in the EPSP waveforms will be analyzed in more detail in Fig. 7.

In the cone, a small potential deflection was detected following the artifact of the current pulse. The amplitude of the deflection was usually less than several $\mathrm{mV}$, so that the deflections were added in the averaging computer (Fig. 3, Average). The waveform was generally biphasic; a negative phase followed by a positive one. A minor difference was recognized between waveforms recorded in dark and light, and this will be analyzed later in relation to the difference in the EPSP waveforms of the horizontal cells (see Fig. 7). The deflections were detectable in about $10 \%$ of the cones penetrated by microelectrodes. Many factors were likely to disturb successful recordings; damage to retinal neurons during surgical isolation of the retina (PINTO and PAK, 1974), injury to cones caused by electrode penetration, progressive deterioration of synaptic activities during the experiment, etc.

The potential deflections were observed in all types of cones; blue-, green-, and red-sensitive ones (Fig. 4). Some of these cones were identified by intracellular Procion dye stainings (not illustrated).

Transretinal current pulse flowing in the opposite direction, i.e., from the 


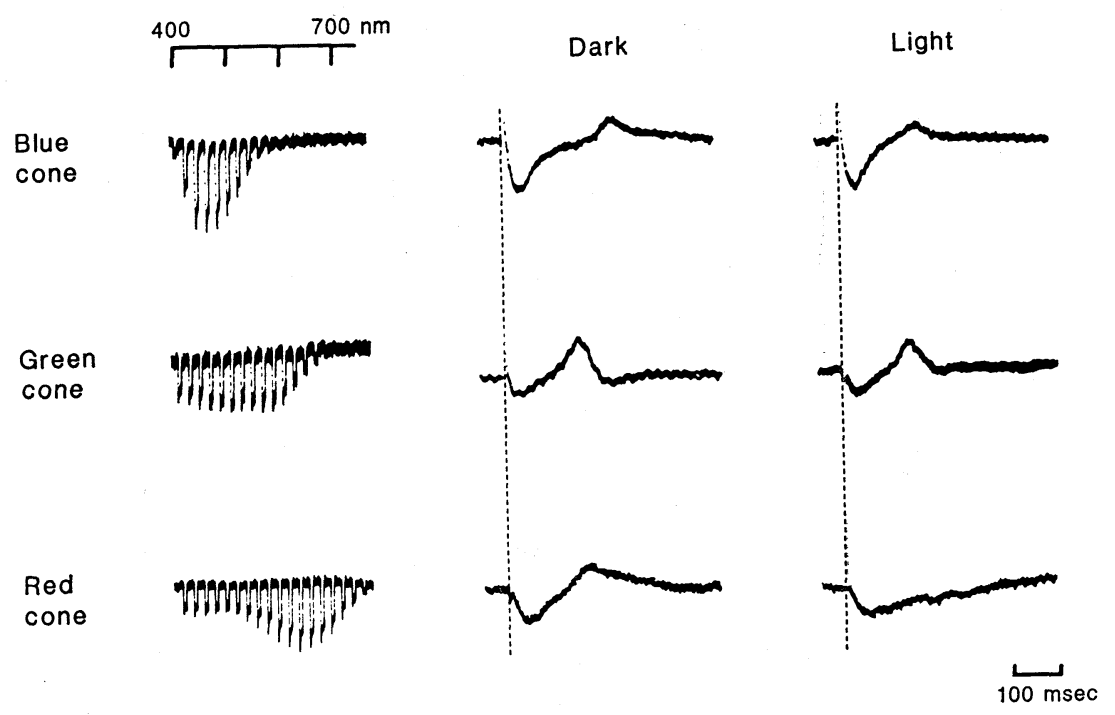

Fig. 4. Responses evoked in three types of cones by transretinal current pulses. The vertical broken lines indicate the timings of transretinal current pulses. The records on the left column are spectral responses of the cones to monochromatic lights $\left(2.9 \times 10^{5}\right.$ photons $\cdot \mu \mathrm{m}^{-2} \cdot \mathrm{sec}^{-1}$ ) scanned from 400 to $740 \mathrm{~nm}$ in steps of $20 \mathrm{~nm}$.

vitreal side to the receptor side, did not evoke any detectable potential change in the cones.

Effects of $\mathrm{Co}^{2+}$ on evoked potential deflection in cones

An early question was whether the potential deflection in the cone was postsynaptic or some sort of electrical responsiveness of cone cell membrane to current pulse stimulation. The latter possibility was excluded by the experimental results shown in Fig. 5. Soon after the retina was perfused with a test solution containing $2 \mathrm{mM} \mathrm{CoCl}_{2}$, a potent synaptic blocking agent (DeMoraes and CARVALHO, 1969; Weakly, 1973; KaneKo and ShimaZaKi, 1976; MuraKami and Shimoda, 1977), the evoked potential deflection in the cone almost disappeared, while the cone itself was still able to respond to light stimulation, though with a slower time course than that in the normal solution. In the $\mathrm{CoCl}_{2}$ solution, all synaptic transmission in the retina was impaired, and the cone under observation was essentially isolated from the functioning of other neurons. Therefore, it was reasonable to conclude that the potential deflection evoked in the cone was postsynaptic. Our conclusion agrees with that of O'BRYAN (1973), who observed in the turtle retina that depolarization of the cone membrane with currents through recording electrodes was ineffective in initiating any detectable potential change in the cone. 


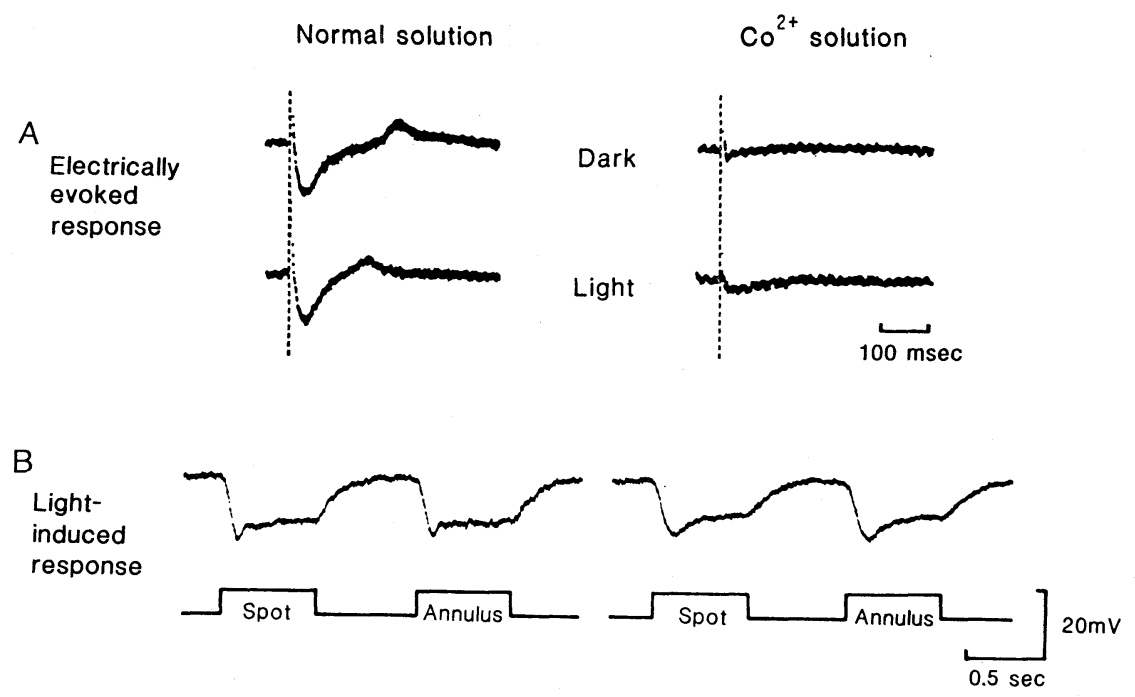

Fig. 5. A : abolition of the electrically evoked response in a cone by perfusion of the retina with a $\mathrm{Co}^{2+}$-containing $(2 \mathrm{~mm})$ Ringer solution. The vertical broken lines indicate the timings of transretinal current pulses. B: light-induced responses recorded from the same cone in the normal (left record) and $\mathrm{Co}^{2+}$-containing (right record) solutions. Patterns of illuminations were the same as used in the experiment shown in Fig. 3.

\section{Effects of polarizing currents on postsynaptic potential in cones}

The waveform of the postsynaptic potential was mostly biphasic - a negative phase followed by a positive one. It was, therefore, of interest to know whether the biphasic form resulted from successively occurring antagonistic processes, i.e. an IPSP followed by an EPSP, or from a single ionic mechanism.

Polarization of the cell membrane is a crucial tool for distinguishing between these two possibilities. If the former is the case, a hyperpolarizing current should diminish the phase of the IPSP, while enhancing the phase of the EPSP. If the latter is the case, on the contrary, both of the phases should have a single reversal potential level in common.

After a control record (Fig. 6, 0 nA) was obtained, the cone was hyperpolarized by passing a D.C. current through a microelectrode. The amplitude of both the negative and positive phases was diminished with increasing current, while the light-induced responses were enhanced (ToYoda et al., 1969). When the current was increased up to $1 \mathrm{nA}$, both phases were almost completely suppressed (Fig. 6, $1 \mathrm{nA}$ ). Because of current noise generated in the electrode, further increase of the currents was not successfully achieved. The effects of hyperpolarizing current suggested that the negative and positive phases had a single equilibrium potential in common at a hyperpolarized level, and that a single postsynaptic ionic mechanism was responsible. An inhibitory postsynaptic potential (IPSP) was the most probable explanation of these observations. 


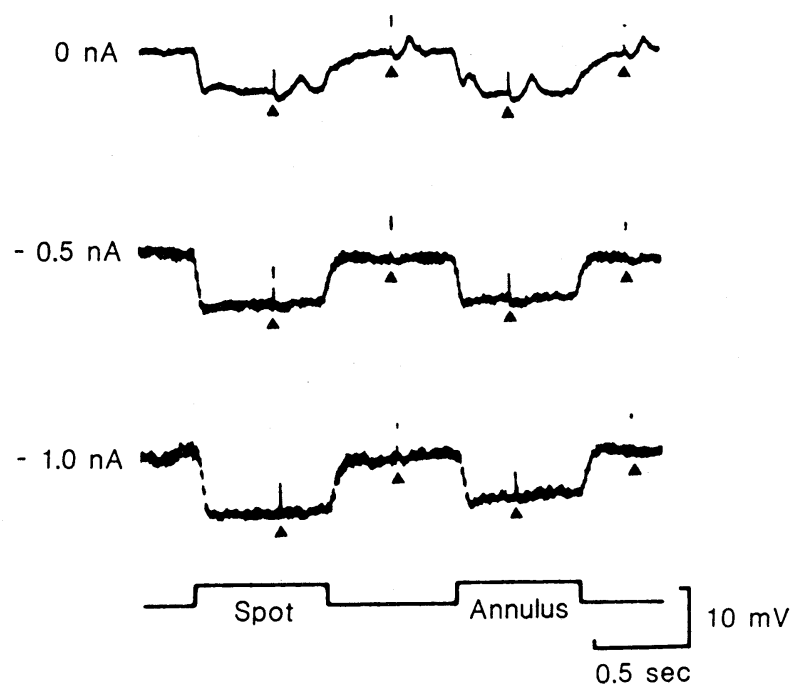

Fig. 6. Effects of extrinsic hyperpolarizing currents on the evoked response in a red-sensitive cone by transretinal current pulse. The hyperpolarizing currents were applied through a microelectrode with intensities as indicated on the left of each record. The triangles attached to the records indicate the timings of transretinal current pulses. Because of the very high resistance of the electrode, the voltage of the hyperpolarized level was difficult to estimate.

The above conclusion should be reconfirmed by application of depolarizing current which would result in enhancement of both phases. However, the experiments were not successful, because much greater electrode noise was produced by depolarizing than by hyperpolarizing current.

\section{Neural mechanism producing biphasic waveform in cones}

The reason why a single postsynaptic ionic mechanism can produce the composite potential waveform in cones is explainable by assuming that cones and horizontal cells are reciprocally interacting with each other by means of positive feedforward and negative feedback synapses. Generally speaking, after the analogy of an electronic circuitry, in this kind of neural system, any transient potential fluctuation caused by some external force rapidly dies away, but is often associated with a damped oscillation. The damping is more prominent when the membrane potentials of both cells are in a "suspended" state, and much less apparent when the membrane potentials are fixed in a fully hyperpolarized state.

These two states are shown in Fig. 7, which displays time courses of the IPSP in the cone and the EPSP in the horizontal cell during dark and light. In the dark, the membrane potentials of both cells were depolarized, but not fully. They were usually at levels between -20 and $-30 \mathrm{mV}$ in cones, and between -20 and $-25 \mathrm{mV}$ in horizontal cells, that is, at "suspended levels." In this 

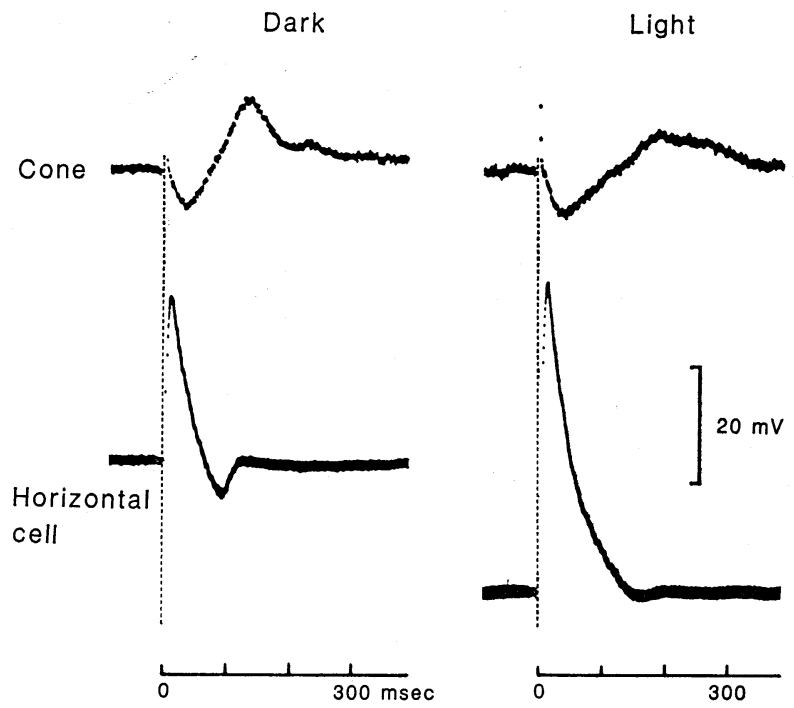

Fig. 7. Time courses of responses in a red-sensitive cone and an $\mathrm{H} 1$ horizontal cell evoked by transretinal current pulses, the timings of which are indicated by the vertical broken lines. All of the records are averages of twenty responses. The difference in base-line levels during dark and light is neglected in the records of cone responses. The calibration of $20 \mathrm{mV}$ applies only to the horizontal cell responses. Further details in the text.

state (Fig. 7, left column), the waveforms of the evoked potentials were biphasic in the cone as well as in the horizontal cell. The latency of the transient EPSP was very short (about $1 \mathrm{msec}$, KANEKO and SHIMAZAKI, 1976); the time to its peak was about $10 \mathrm{msec}$, and a marked transient hyperpolarization followed (BYzov and TRIFonOv, 1968). In the cone, a negative phase reached its peak about $25 \mathrm{msec}$ later than that of the EPSP of the horizontal cell, and a prominent positive phase followed. When the membrane potentials of the cells were hyperpolarized by steady white light illumination (Fig. 7, right column), the EPSP in the horizontal cell appeared with a latency and time to peak similar to those in the dark. However, the waveform was almost monophasic. In the cone, the time to a negative peak was comparable to that in the dark, but the following positive phase was much smaller. From these observations, it seemed likely that the waveform in the cone was closely related to that in the horizontal cell.

A sequence of neural and synaptic events resulting in the biphasic waveform in the cone was considered to occur in the following way. When the horizontal cell was depolarized by a transretinal current pulse, an inhibitory neurotransmitter was liberated, and the IPSP was produced in the cone. The IPSP reduced release of an excitatory (depolarizing) transmitter from the cone, thereby resulting in the hyperpolarization in the horizontal cell. Its amplitude could be large if the horizontal cell membrane was at a "suspended" potential level, while small when 
the membrane was fixed at the fully hyperpolarized level. This hyperpolarization, in turn, caused release of a lesser amount of the inhibitory neurotransmitter from the horizontal cell. The IPSP in the cone was then reduced, resulting in a depolarization, that is, the positive phase. In summary, the biphasic form of the potential deflection in the cone reflected the time sequence of variable states of the IPSP; starting from the intermediate state, swinging down closely to the IPSP equilibrium potential, and then swinging up to the level near the resting membrane potential of the cone.

\section{Effects of GABA on the IPSP in cones}

The results so far described suggest that the horizontal cells exert a negative feedback onto cones. If so, then a logical next step is to identify the neurotransmitter that mediates the feedback. Since GABA has been suggested (see Introduction), experiments were designed to test effects of GABA on the IPSP in the cones.

$$
\text { Normal solution GABA solution }
$$

A

Cone
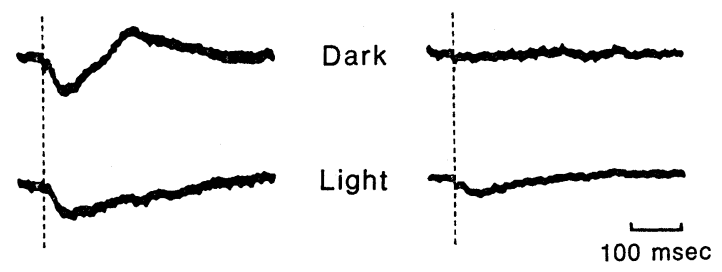

B

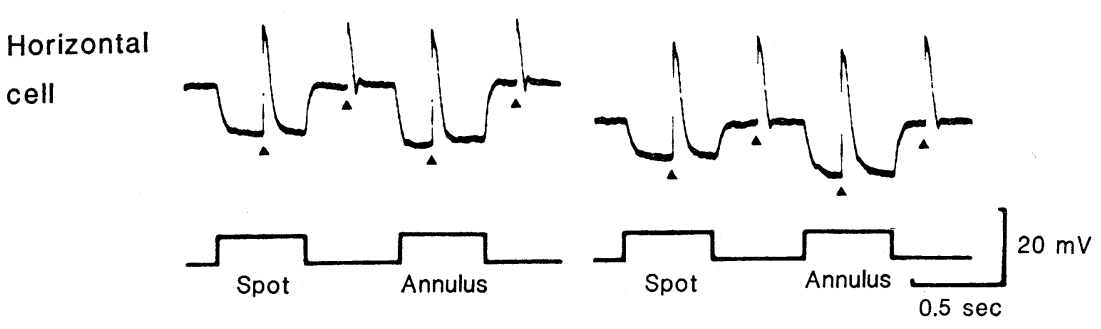

Fig. 8. A: diminution of the electrically evoked response (IPSP) in a cone by perfusion of the retina with a GABA-containing solution $(5 \mathrm{~mm})$. The responses were averaged twenty times. The records in A are displayed regardless of a shift of membrane potential level caused by GABA application ( $c f$. Fig. 9). B: after the records in A were obtained and the retina was washed out by the normal solution, the electrode was advanced into an $\mathrm{H} 1$ horizontal cell, and the GABA-solution was administered again. The records show that GABA does not impair the feedforward synaptic transmission from cones to horizontal cells. The vertical broken lines in A and the triangles in B indicate the timings of transretinal current pulses. (Revised from MURAKAMI et al., 1978, by the permission of Sensory Processes) 
Figure 8 shows the result obtained from a red-sensitive cone. After obtaining control records of the evoked IPSP's during perfusion with a normal solution (Fig. 8A, left column), a GABA-containing (5 mM) solution was administered. The IPSP's gradually diminished, and were almost completely abolished a few minutes later (Fig. 8A, right column). Recovery after switching back to the normal solution was not successfully observed, since the microelectrodes did not stay long enough inside the cells tested. However, such experiments on six cones showed similar effects of GABA on the IPSP's.

After the electrode slipped out of the cone and the retina was washed out with the normal solution, the electrode was farther advanced into an H1 horizontal cell, and the GABA solution was administered again. As shown in Fig. 8B, even in the presence of GABA, transient EPSP's were still generated in horizontal cells. These observations indicated that the abolition of the IPSP in the cone was not due to impairment of the feedforward synaptic transmission, but due to desensitization of the feedback synapse caused by GABA.

\section{Effects of GABA on light-induced responses in cones}

The above experiment suggested the presence of a GABA-sensitive postsynaptic site in the cones. If this is the case, perfusion of the retina with GABA solution should hyperpolarize the membrane of the cones, since GABA is commonly known as a potent inhibitory neurotransmitter.

Figure 9 shows such an effect of GABA observed on a green-sensitive cone. After recording spectral responses in the normal solution (Fig. 9A), the retina was alternately illuminated by a spot and annulus of white light. After the GABA (5 mM) solution was applied, the dark level (the membrane potential in the dark) hyperpolarized by several $\mathrm{mV}$, associated with a diminution of amplitudes of light-

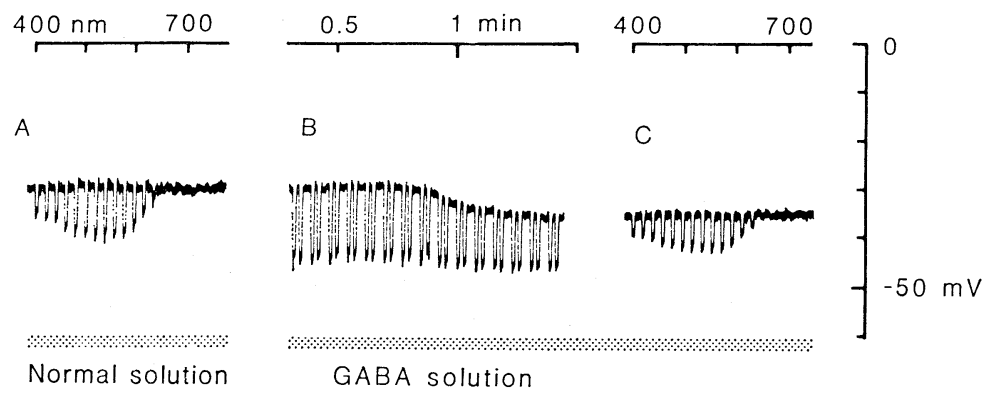

Fig. 9. Effects of GABA ( $5 \mathrm{~mm})$ solution on cone responses. A: spectral responses of the cone in the normal solution (green-sensitive cone). B: hyperpolarization of the dark level caused by GABA. The retina was illuminated alternately by spot and annulus. The upper scale indicates the time of perfusion, starting when the test solution reached the perfusion chamber. $C$ : spectral responses of the cone recorded when the cone was maximally hyperpolarized by GABA. (Revised from Murakami et al., 1978, by the permission of Sensory Processes) 
induced responses (Fig. 9B). When the effect of GABA was maximal, spectral responses were recorded again (Fig. 9C). The response amplitude was greatly reduced, probably because GABA caused a membrane conductance increase at the postsynaptic site, and therefore partially shunted the light-induced responses.

\section{DISCUSSION}

The presence of the negative feedback from horizontal cells to cones has been suggested by several electrophysiological studies (BAYLOR et al., 1971; O'BRYAN, 1973; BURKHARDT, 1977; see also Introduction). The suggestion was derived mainly from the observation that, in the retinas of the turtle, pikeperch and tiger salamander, a depolarizing potential was produced in cones when horizontal cells were hyperpolarized. An identical depolarizing potential was also detected in carp retina (Fig. 2), indicating that the feedback mechanism is basically similar between such animal classes so far studied as the turtle, fish, and salamander. However, little else is known about the nature of this synapse.

The present experiment showed that the negative feedback is a conventional inhibitory synapse which is activated when horizontal cells are depolarized (Figs. 3 through 8). Therefore, it is reasonable to suppose that the feedback is continuously active in the dark and produces an IPSP in cones. When horizontal cells are hyperpolarized by light, the feedback is reduced and the IPSP is diminished, resulting in a shift of the cone membrane potential to depolarization (Fig. 2). This is a probable explanation for the depolarizing synaptic potential produced in a cone by annular illumination.

Membrane conductance change associated with the depolarizing potential in cones. If the above view is correct, the depolarizing potential in cones is, in fact, a consequence of a decrease of IPSP, and should be associated with a membrane conductance decrease.

The experiments carried out so far gave divergent results. Those on turtle cones (BAYLOR et al., 1971) and on salamander cones (LASANSKY, 1981) suggested a conductance increase. However, another study on turtle cones demonstrated two separate depolarizing components with different time courses and reversal potentials, one of which was associated with an increase and the other with a decrease of conductance (O'BRYAN, 1973). Recently, Gerschenfeld and others (Gerschenfeld and Piccolino, 1980; Gerschenfeld et al., 1980) showed that the depolarization was accompanied by a conductance increase due to $\mathrm{Ca}^{2+}$ channel activation which frequently became regenerative to produce spikes. In addition, they proposed a hypothesis that the horizontal cell transmitter released in the dark increases either the $\mathrm{K}^{+}$or $\mathrm{Cl}^{-}$conductance, preventing its regenerative activation.

In the present experiment, no attempt was made to identify ion species related to the IPSP generation in the carp cone; however, $\mathrm{K}^{+}$or $\mathrm{Cl}^{-}$has been the usual 
candidate in neural systems other than the retina. If this is the case, the $\mathrm{K}^{+}$or $\mathrm{Cl}^{-}$conductance increase, proposed by Gerschenfeld and others, may lead to the IPSP which we observed in the carp cones. No evidence has been adduced yet in support of $\mathrm{Ca}^{2+}$ channel activation in fish cones. Further studies, with special reference to comparative neurophysiology, are necessary to obtain a generalized view of the ionic mechanisms of the depolarizing potential in the vertberate cones.

Effective concentration of GABA. In the present experiment, GABA is suggested to be a putative neurotransmitter mediating the feedback. Externally applied GABA hyperpolarized the cone membrane (Fig. 9) and abolished the IPSP in cones (Fig. 8). However, the relatively high concentration of GABA $(5 \mathrm{~mm})$ we used makes it doubtful that GABA is a genuine transmitter. For example, it has been reported that, at the crayfish inhibitory neuromuscular junction, a much lower concentration $\left(10^{-4} \mathrm{M}\right.$ or less) is effective in increasing the membrane conductance (TAKEUCHI and TAKEUCHI, 1969).

We had to use such a high concentration because of technical difficulties. As cones are minute cells, the electrode did not stay intracellularly located long enough to observe slowly appearing effects from lower concentrations of GABA. If one also considers the high-affinity uptake mechanisms of GABA into horizontal cells (MARC et al., 1978), it is reasonable to suppose that the concentration of externally applied GABA is gradually reduced during diffusion en route to the GABA-sensitive site in cones, and that the final concentration does not differ greatly from the effective concentration at the invertebrate neuromuscular junction.

Morphological basis of the feedback. In spite of many electrophysiological and neuropharmacological studies suggesting the presence of the feedback, little is known about its morphology. To our knowledge, a likely structure has been observed only in the catfish retina (DAVIS and NAKA, 1980); a horizontal cell makes a chemical synapse onto a small, unidentified process which is tentatively presumed to be a receptor telodendron. Because of the importance of this synapse, it would be desirable if the electrophysiological data could be supported by morphological observations.

We are grateful to Dr. Peter Gouras for helpful criticism and for correcting the English. This work was supported by Grants-in-Aid for Scientific Research from the Ministry of Education, Science and Culture of Japan (Nos. 421821, 448104, and 520920), the Ministry of International Trade and Industry of Japan (Bionics Research Grant) and Keio Gijuku Academic Development Funds to M. M., the Grant for Promotion of Medical Sciences from Keio University School of Medicine to Y.S., and the grants from the Keio Medical Association to E. M. and S. W.

\section{REFERENCES}

Baylor, D. A. and Fuortes, M. G. F. (1970) Electrical responses of single cones in the retina of the turtle. J. Physiol. (Lond.), 207: 77-92. 
Baylor, D. A., Fuortes, M. G. F., and O’Bryan, P. M. (1971) Receptive fields of cones in the retina of the turtle. J. Physiol. (Lond.), 214: 265-294.

BurkhardT, D. A. (1977) Responses and receptive-field organization of cones in perch retinas. J. Neurophysiol., 40: 53-62.

BurkhaRdt, D. A. and Hassin, G. (1978) Influences of cones upon chromatic- and luminositytype horizontal cells in pikeperch retinas. J. Physiol. (Lond.), 281: 125-137.

Byzov, A. L. and Trifonov, Yu. A. (1968) The response to electric stimulation of horizontal cells in the carp retina. Vision Res., 8: 817-822.

Davis, G. W. and NAKA, K.-I. (1980) Synaptic communication in the catfish outer plexiform layer: Structure and function. In: Information Processing in the Nervous System, ed. by Pinsker, H. M. and Willis, W. D., Jr. Raven Press, New York, pp. 221-240.

DeMoraes, S. and Carvalho, F. V. (1969) On the mechanism of neuromuscular blocking action of cobalt ion. Pharmacology, 2: 237-242.

Djamgoz, M. B. A. and Ruddock, K. H. (1979) Effects of picrotoxin and strychnine on fish retinal S-potentials: Evidence for inhibitory control of depolarizing responses. Neurosci. Lett., 12: 329-334.

Fuortes, M. G. F., Schwartz, E. A., and Simon, E. J. (1973) Colour-dependence of cone responses in the turtle retina. J. Physiol. (Lond.), 234: 199-216.

Fuortes, M. G. F. and Simon, E. J. (1974) Interactions leading to horizontal cell responses in the turtle retina. J. Physiol. (Lond.), 240: 177-198.

Gerschenfeld, H. M. and Piccolino, M. (1980) Sustained feed-back effects of L-horizontal cells on turtle cones. Proc. R. Soc. Lond. B, 206: 465-480.

Gerschenfeld, H. M., Piccolino, M., and Neyton, J. (1980) Feed-back modulation of cone synapses by L-horizontal cells of turtle retina. J. Exp. Biol., 89: 177-192.

Gouras, P. (1972) S-potentials. In: Handbook of Sensory Physiology, Vol. VII/2, Physiology of Photoreceptor Organs, ed. by Fuortes, M. G. F. Springer-Verlag, Berlin, pp. 513-529.

GrahaM, L. T., Jr. (1974) Comparative aspects of neurotransmitters in the retina. In: The Eye, Vol. 6, ed. by Davson, H. and Graham, L. T., Jr. Academic Press, New York, pp. 283-342.

KANEKo, A. and ShimazaKi, H. (1976) Synaptic transmission from photoreceptors to bipolar and horizontal cells in the carp retina. Cold Spring Harbor Symp. Quant. Biol., 40: 537-546.

LAM, D. M. K. (1975) Biosynthesis of $\gamma$-aminobutyric acid by isolated axons of cone horizontal cells in the goldfish retina. Nature, 254: 345-347.

LAM, D. M. K. (1976) Synaptic chemistry of identified cells in the vertebrate retina. Cold Spring Harbor Symp. Quant. Biol., 40: 571-579.

LAm, D. M. K. and Steinman, L. (1971) The uptake of $\left[\gamma-{ }^{3} \mathrm{H}\right]$ aminobutyric acid in the goldfish retina. Proc. Natl. Acad. Sci. U.S.A., 68: 2777-2781.

Lam, D. M. K., Su, Y. Y. T., Swain, L., Marc, R. E., Brandon, C., and Wu, J.-Y. (1979) Immunocytochemical localisation of L-glutamic acid decarboxylase in the goldfish retina. Nature, 278: 565-567.

LASANSKY, A. (1981) Synaptic action mediating cone responses to annular illumination in the retina of the larval tiger salamander. J. Physiol. (Lond.), 310: 205-214.

Marc, R. E., Stell, W. K., BoK, D., and LAM, D. M. K. (1978) GABA-ergic pathways in the goldfish retina. J. Comp. Neurol., 182: 221-245.

MuraKami, M. and Shimoda, Y. (1977) Identification of amacrine and ganglion cells in the carp retina. J. Physiol. (Lond.), 264: 801-818.

Murakami, M., Shimoda, Y., and Nakatani, K. (1978) Effects of GABA on neural activities in the distal retina of the carp. Sens. Processes, 2: 334-338.

Murakami, M., Shimoda, Y., Nakatani, K., MiYachi, E., and Watanabe, S. (1982) GABAmediated feedback and color opponency in carp retina. Jpn. J. Physiol., 32: 927-935.

Vol. 32, No. 6, 1982 
O'Bryan, P. M. (1973) Properties of the depolarizing synaptic potential evoked by peripheral illumination in cones of the turtle retina. J. Physiol. (Lond.), 235: 207-223.

Piccolino, M. and Gerschenfeld, H. M. (1980) Characteristics and ionic processes involved in feedback spikes of turtle cones. Proc. R. Soc. Lond. B, 206: 439-463.

PINTO, L. H. and PAK, W. L. (1974) Light-induced changes in photoreceptor membrane resistance and potential in gecko retinas. II. Preparation with active lateral interactions. $J$. Gen. Physiol., 64: 49-69.

Shimoda, Y., Miyachi, E., Watanabe, S., and Murakami, M. (1982) Effects of GABA antagonists on spectral responses of horizontal cells in the carp retina. Color Res. Appl., 7: 149-151.

TAKeuchi, A. and TAKeuchi, N. (1969) A study of the action of picrotoxin on the inhibitory neuromuscular junction of the crayfish. J. Physiol (Lond.), 205: 377-391.

Tomita, T., Kaneko, A., Murakami, M., and Pautler, E. L. (1967) Spectral response curves of single cones in the carp. Vision Res., 2: 519-531.

Toyoda, J.-I., NosaKI, H., and Tomita, T. (1969) Light-induced resistance changes in single photoreceptors of Necturus and Gekko. Vision Res., 9: 453-463.

Trifonov, Yu. A. (1968) Study of synaptic transmission between photoreceptors and horizontal cells by means of electric stimulation of the retina. Biofizika, 13: 809-817.

Trifonov, Yu. A. and Byzov, A. L. (1977) Interaction in photoreceptor synapses revealed in experiments with polarization of horizontal cells. In: Vertebrate Photoreception, ed. by Barlow, H. B. and FAtT, P. Academic Press, London, pp. 251-263.

Trifonov, Yu. A., Byzov, A. L., and Chailahian, C. M. (1974) Electrical properties of subsynaptic and nonsynaptic membranes of horizontal cells in fish retina. Vision Res., 14: 229-241.

VoAden, M. J. (1976) Gamma-aminobutyric acid and glycine as retinal neurotransmitters. In: Transmitters in the Visual Process, ed. by Bonting, S. L. Pergamon Press, Oxford, pp. 107-125.

WAtANABe, K., KATAGIRI, Y., and SudA, Y. (1978) Electrically evoked responses (E-responses) of L- and C-type horizontal cells in the carp retina. Sens. Processes, 2: 326-333.

WeAKLY, J. N. (1973) The action of cobalt ions on neuromuscular transmission in the frog. J. Physiol. (Lond.), 234: 597-612. 